\title{
Category-specific naming preservation: a single case study
}

\author{
PAT M C KEN NA A N D ELIZABETH K. WARRINGTON \\ From The National Hospital, Queen Square, London
}

SUM MARY The report of this single case study describes the preservation of a simple semantic category in a severely anomic patient. The implications for the organisation of semantic knowledge are discussed.

Recent investigations of aphasic patients provide evidence for the increasingly complex organisation of semantic knowledge systems. Clinical studies have reported differential impairments in recognising (identifying) and in naming objects presented in the visual, verbal, and tactile modalities (Spreen et al., 1966; Geschwind, 1967; Warrington, 1975). In addition to comparisons between modalities, recent research has probed characteristics within modalities, and evidence here implicates the categorical organisation of semantic knowledge. It is widely accepted in the neurological literature that selective anomias for objects, symbols, and colours can occur. Geschwind differentiates such circumscribed deficits from the classical anomia where the naming impairment appears generalised. On the other hand Goodglass et al. (1966) claimed that the homogeneity of a nominal impairment is often more apparent than real, and showed that the differential capacity for naming and for word comprehension in different semantic categories is "a regular characteristic of aphasia." In a population of 135 aphasic patients they found that the relative difficulty of naming objects, colours, numbers, letters, and actions was different in a group of Broca's aphasics from a group of Wernicke's aphasics-and moreover the relative difficulty in these five semantic categories was to some extent independent of order of difficulty for word comprehension. More recently Yamadori and Albert (1973) reported a single case study of a patient with a generalised nominal deficit (except that colours were spared) who failed to comprehend words from only two categories-"body

Address for reprint requests: Dr Elizabeth K. Warrington, Psychology Department, The National Hospital, Queen Square, London WCIN 3BG.

Accepted 3 January 1978 parts" and "common room objects." In view of these pointers to category-specific comprehension deficits they suggested that a word sound must first be identified as to category before the full word meaning could be achieved. Similarly, Warrington (1975) reported a differential effect of word concreteness. One patient (AB) had significantly greater difficulty in comprehending concrete words than abstract words, whereas the converse was the case for a second patient (EM).

In summary, there appears to be some evidence for category specificity both for word retrieval (naming) and for word comprehension and, furthermore, there is some suggestion that these two systems do not operate in parallel. The present case study provides a striking example of category-specific preservation of naming abilities in that one category, "countries," was found to be relatively spared in a patient who otherwise showed a severe and prima facie global nominal dysphasia. This patient further illustrates the phenomenon of greater competence for word retrieval than word comprehension within a single semantic category.

\section{Patient}

The patient (FC) was a 53 year old sales manager engineer who was admitted to the National Hospital for Nervous Diseases after a four week history of progressive right sided weakness and language disturbance. $\mathrm{He}$ was referred as an emergency when his deteriorating condition required immediate surgery. A large left temporal lobe tumour, extending posteriorly to the parietal lobe, was excised, and histology showed it to be a secondary deposit from a carcinoma of the stomach for which he had undergone surgery a year previously. 
PSYCHOLOGICAL ASSESSMENT

The patient was first seen in the Psychology Department of the National Hospital one week after operation. On set 1 of the Advanced Progressive Matrices he scored seven out of 12 which is average for his age. Routine tests of perceptual and spatial skills were performed at an average or above average level-for example, unusual view objects 20 out of 20 ; cube analysis 14 out of 16 . On a visual recognition memory test he scored 40 out of 50 which is within the average range for his age. In contrast, most language functions were markedly impaired. On two naming tests (see Coughlan and Warrington, 1978) he scored nought out of 15 and one out of 15 respectively. On a modified version of the Token Test of Comprehension he scored nought out of 15 . On the Oldfield Picture Naming Test he scored one out of 36. His word fluency was very poor in so far as he was only able to give one word beginning with the letter $\mathrm{S}$ in two minutes, and no animal names. $\mathrm{He}$ was unable to read or spell any words from the Schonell Graded Reading or Spelling Tests. It is evident that he had a severe global dysphasia in which all aspects of language function were impaired.

During testing it was observed that FC was often able to produce names of countries, and would on occasion resort to saying countries as a method of communication. For example, when attempting to identify a photograph of Ghandi he responded "India". It was to explore this observation more fully that the following experiment was designed.

\section{Experiment}

\section{MATERIALS}

Five categories-body parts, colours, animals, objects, and countries-were chosen and 10 items from each of these categories selected. All items were of high frequency (A or AA-Thorndike Lorge). The Thorndike Lorge count for countries may not be appropriate to an English population and it was necessary to introduce "Scotland" to make up the pool of 10 common countries. The items of the other categories were selected to be easily recognisable in pictorial form, and a visual representation of each of the 50 items was prepared in the form of clear line drawings except for colours where a colour patch (approximately one inch square) was used as the visual stimulus. In the case of countries clear outline drawings were prepared.

PROCEDURE

Three conditions to test FC's word retrieval and word comprehension skills were devised; he completed this experiment without any changes of procedure on two consecutive days. The tests were administered in the following order:

\section{Naming - visual presentation}

The total pool of 50 drawings (10 from each of five categories) were presented singly, a Latin square design being adopted to control for category order effects. No time limit was enforced, thus enabling FC to pace himself. Each response was scored correct or incorrect.

\section{Naming comprehension}

The pictorial form of the 10 items from a single category were presented in an array. Each name was spoken by the examiner and FC was required to point to the named item. The order of testing recognition of the 10 items for each category was as follows: colours, objects, animals, parts of the body, and countries. Each item was scored correct or incorrect.

3. Naming from description-auditory presentation A verbal question was devised to elicit the name of the 50 items described above-for example, what is the name of the animal which barks? what colour is grass?; what is the name of the organ of sight?; what writing instrument is used with ink?; the Stars and Stripes is the flag of what country? Each item was presented in the identical order as for condition 1 in which FC attempted to nameo the drawing. Each item was scored correct oro incorrect.

\section{Results}

The correct responses for each condition of testing for each of the five categories are given in Table 1 (summing the responses across days). A measure of the patient's total competence for each category was obtained by taking the mean correct response for each category (summing across conditions). It appears from these results that there was a differential effect both of category and of condition of testing.

Table 1 Correct responses

\begin{tabular}{lccccccc}
\hline & Colour & Objects & Countries & $\begin{array}{l}\text { Body } \\
\text { parts }\end{array}$ & Animals & Mean \\
\hline $\begin{array}{l}\text { Naming- } \\
\text { visual }\end{array}$ & 0 & 2 & 13 & 10 & 1 & 5 \\
$\begin{array}{l}\text { presentation } \\
\text { Naming- } \\
\text { comprehension }\end{array}$ & 17 & 19 & 20 & 7 & 19 & 16 \\
$\begin{array}{l}\text { Naming from } \\
\text { description- } \\
\text { auditory } \\
\text { presentation }\end{array}$ & 0 & 2 & 15 & 0 & 1 & 4 \\
\begin{tabular}{l} 
Mean \\
\hline
\end{tabular} & 6 & 8 & 16 & 6 & 7 & 8 \\
\hline
\end{tabular}


A completely randomised analysis of variance (days $\times$ condition $\times$ category) was computed, with 10 binary replications per cell. The main effects (day of testing, condition of testing, and category of item) and the interaction terms are given in Table 2. Though there was a significant difference between FC's performance on day 1 and day 2 $(F(1,270)=4.98 ; P<0.05)$, inspection of the data shows this to be one of degree rather than kind, and lack of significant interaction effect $(F(8,270)$ $=0.74 ; P<0.1)$ between day and condition and category indicates that the pattern of results over time remained constant.

Table 2 Main effects and interaction terms

\begin{tabular}{lrll}
\hline Source & \multicolumn{1}{l}{ F } & $d f$ & Significance \\
\hline Day & 4.98 & 1 & $<0.05$ \\
Condition & 126.28 & 2 & $<0.001$ \\
Category & 29.28 & 4 & $<0.001$ \\
Day $\times$ condition & 2.91 & 2 & NS \\
Day $\times$ category & 0.48 & 4 & NS \\
Condition $\times$ category & 12.57 & 8 & $<0.001$ \\
Day $\times$ condition $\times$ category & 0.74 & 8 & NS \\
\hline
\end{tabular}

The effect of condition of testing, that is naming, comprehension, and naming from description was highly significant $(F(2,270)=126.28 ; P<0.001)$. Table 1 shows this result to derive clearly from the overall superiority of recognition $(82 \%$ correct) compared with the two conditions involving word retrieval $(26 \%$ and $18 \%$ correct respectively). This finding is commonplace for both normal and dysphasic populations.

The first pertinent result was that there was a highly significant effect of category $(F(4,270)=$ 29.28; $\mathrm{P}<0.001$ ). Inspection of Table 1 shows that this differential effect of categories derives from FC's far superior ability to retrieve country names (under each condition). A chi-squared test comparing countries to the next highest scoring category (objects) confirmed this hypothesis $\left(\chi^{2}(\mathrm{df} .1)=8.6, \mathrm{P}<0.01\right)$.

The second pertinent finding was the significant interaction between condition and category $(\mathrm{F}(8,270)=12.57 ; \mathrm{P}<0.001)$. There was a differential effect of the condition of testing on the categories. Inspection of the correct scores in Table 1 shows a departure from the normal pattern of superior recognition to naming with regard to the body parts category.

\section{Discussion}

This study provides an instance of categoryspecific naming preservation in a severely anomic patient. It was shown that his naming of "countries" was consistently superior to that of any other explored category. This finding held whether the name was elicited through the visual or verbal modality. Furthermore, his name comprehension for countries was totally reliable. It would seem reasonable to infer from these findings that some specific category of his semantic knowledge remains comparatively accessible in the midst of a severe naming impairment and some disturbance of name comprehension. This observation is consistent with the data of Goodglass et al. and suggests that the organisation of semantic knowledge is perhaps even more fine grain than had hitherto been supposed. This specificity of naming skills in a patient with a localised cerebral lesion implies a structural as well as functional basis for this organisation within semantic knowledge systems. Previously Warrington (1975) stressed the hierarchical properties of the semantic knowledge systems in demonstrating the relative preservation of superordinate categories and the vulnerability of subordinate categories. For example, patients with word comprehension difficulties were often able to classify the spoken word "carrot" as a plant but unable to classify it either as a vegetable or something one eats. The present findings add a further dimension to the structural basis of such word meaning systems in so far as it would appear that there is an ordered organisation both within and between categories.

The present evidence also confirms the previously reported (Goodglass et al., 1966) discrepancy between verbal output and verbal comprehension of body parts, in that retrieval of a name occurred in the absence of understanding of that same name. This reversal of the usual relationship between name retrieval and name comprehension was obtained for only one category, and thus provides further evidence for category specific organisation of word meanings. Following Geschwind (1965), it is not implausible to accept a disconnection explanation for the modalityspecific comprehension deficits (for a full discussion of this problem see Warrington and Shallice, in preparation). That this discrepancythe failure to comprehend spoken names with relatively preserved naming with visual inputoccurred with only one category is more problematical for the disconnection views but entirely consistent with Warrington's notions of modality-specific meaning systems.

We are grateful to $\mathrm{Mr} \mathrm{L}$. Walsh for permission to investigate his patient and report our findings. We wish to thank Dr R. T. C. Pratt and Dr E. 
Golding for their assistance and advice in the preparation of this manuscript. We are particularly grateful to Dr P. J. Barber for his statistical advice.

\section{References}

Coughlan, T., and Warrington, E. K. (1978). Wordcomprehension and word-retrieval in patients with localised cerebral lesions. Brain. In press.

Geschwind, N. (1965). Disconnection syndromes in animals and man. Brain, 88, 237-294 and 585-644.

Geschwind, N. (1967). The varieties of naming errors.
Cortex, 3, 97-112.

Goodglass, H., Klein, B., Carey, P., and Jones, K. J. (1966). Specific semantic word categories in aphasia. Cortex, 2, 74-89.

Spreen, O., Benton, A. L., and Van Allen, M. W. (1966). Dissociation of visual and tactile naming in amnesic aphasia. Neurology (Minneapolis), 16, 807814.

Warrington, E. K. (1975). The selective impairment of semantic memory. Quarterly Journal of Experimental Psychology, 27, 635-657.

Yamadori, A., and Albert, M. I. (1973). Word category aphasia. Cortex, 9, 112-125. 